\title{
Grade 1 teachers' knowledge and perceptions regarding reading instruction in Windhoek, Namibia
}

\author{
Pamela J. February ${ }^{1}$ \\ University of Namibia
}

\begin{abstract}
A number of international and national assessments show that Namibian children are not reading according to set benchmarks. The teaching and learning of reading can only be as good as the teachers who facilitate the reading acquisition process. Namibian learners are formally taught how to read in Grade 1, and thus this article focuses the perceptions of Grade 1 teachers in Windhoek, Namibia regarding their knowledge and classroom practices in teaching reading and how they support their learners' reading acquisition. Through a survey to gauge their use of reading practices, 132 teachers were asked about the teaching methods they use, the specific instruction content they use, how they create a literate classroom, how they encourage and support poor readers, and whether and how reading instruction in small groups occurs. Their teacher training was examined, as well as the knowledge that they have regarding certain language and reading components that support reading instruction. Teachers reported that they mostly use a range of methods when teaching reading $(83 \%)$, while (15\%) report using only one method. Of all the reading and language skills that teachers had to select from, $90 \%$ included phonological awareness as part of their reading instruction content, more so than the other reading and language skills. Among different strategies used to create a literate environment in the classroom, the majority (82\%) use labels and notices to draw children's attention to literacy. To encourage struggling readers to read, teachers indicated they mainly use simple, easy texts so that poor readers can experience success. The results of the study reveal that while most Grade 1 teachers $(81 \%)$ claim that they have received average to excellent training in teaching reading and demonstrate that they overwhelmingly agree (99\%) with good reading practices and beliefs, the results reveal that their actual knowledge of various aspects of reading does not relate to their stated teacher training and reading beliefs. It appears that the overall average for the knowledge section showed that less than $37 \%$ of teachers had detailed knowledge of specific aspects of reading such as being able to identify syllables, morphemes, and speech sounds in words as well as demonstrating knowledge of phonics, phonemes, and diphthongs. The article discusses some strategies to alleviate some of the issues highlighted in the results.
\end{abstract}

Keywords: reading skills, reading instruction, teacher knowledge; Namibia

\section{Introduction}

In spite of Namibia's focus on education as a means to empower the nation, recent national results show that for learners who sat for the Grade 12 examination in 2019 only $33.7 \%$ of the total obtained a $D$ grade and above in English. This is below the target of $35 \%$ set under the Fifth National Development Plan. According to the Deputy Minister of Education, Arts and

\footnotetext{
${ }^{1}$ Dr Pamela J. February is a lecturer in the Faculty of Education (Department of Educational Psychology and Inclusive Education) at the University of Namibia. Her areas of interest and expertise are in reading acquisition and fluency; vocabulary acquisition; inclusive education practices; hearing impairment; and the use of technology to enhance childhood learning, especially reading and Mathematics. These are also the areas in which she supervises undergraduate and postgraduate students. Email: pfebruary@unam.na
} 
Culture, Ms Anna Nghipondoka, in a statement made to The Namibian newspaper on 20 January 2020, "the persistent poor results in English was a cause of concern as it deprives a lot of pupils a chance to get admitted to institutions of higher learning..." (likela \& Oliviera, 2020 , p. 1). This situation is the culmination of 12 years of education and in order to attempt to remedy this situation, we need to examine the foundation of how learners are taught to read. In order to do this, we begin with the teachers who teach reading. This article investigates the perceptions of Grade 1 teachers in Namibia regarding their knowledge and classroom practices in teaching reading and how they support their learners' reading acquisition.

The following literature review is based on the main questions asked in the survey to discover what the literature and research state about these pertinent aspects of teachers' knowledge and perceptions regarding teaching reading in the early grades. These aspects include teacher training as it relates to reading instruction, languages used in teaching reading, teaching methods, classroom practices, and class size.

\section{Literature Review \\ Teacher training}

A teacher's capacity to ensure the success of early-grade reading is key to the child's learning of reading (Trudell, Dowd, Piper, \& Bloch, 2012). For this to happen, teachers need to be welltrained, mentored, and supported on an ongoing basis, especially when new reading programs are introduced. Moats (1999) describes the competencies in which teachers should be trained. She states that effective teacher training in reading instruction should include: the knowledge of basic psychological processes encompassed in reading; how children develop reading skills; the difference between good and poor readers; how the language is structured so that the most effective practices to teach reading in that language are used; and the use of research-proven principles of effective reading instruction. Using this knowledge, teachers should exhibit effective teaching skills that include the ability to prepare and present lessons that cater to a range of learners with different abilities, select the most appropriate researchproven teaching methods and materials, and employ assessment strategies that will inform tailored teaching.

According to the United Nation Educational, Scientific and Cultural Organisation (UNESCO) report of the assessment of teacher training and development needs in Namibia, the overall percentage of qualified primary teachers grew from $41 \%$ in 2001 to $78 \%$ (77\% female) in 2012; at the secondary level, it grew from 73\% in 2001 to $93 \%$ (93\% female) in 2012 (UNESCO, 2013). Although the number of qualified teachers in Namibia has increased, there is a need to examine the quality of teacher training, especially regarding reading instruction in the lower primary grades. The Early Grade Reading Assessment (EGRA) results and lessons learned indicate that teacher education programs across many Sub-Saharan African countries do not offer specific training for teaching reading in the mother tongue, and this would affect how junior primary teachers teach reading across the languages. Researchers from the Project for the Study of Alternative Education in South Africa (PRAESA), affiliated with the University of Cape Town, found that in Southern Africa (including Namibia), teachers were not properly trained how to teach reading and writing in the mother tongue and English as an additional language.

Because most Namibian junior primary teachers were trained at the previous colleges of education, there is a need to examine the training that they have received in reading instruction as part of their three-year Basic Education Teachers' Diploma (BETD). There is also a need to examine what has been offered at the University of Namibia since 2011 and what the Bachelor of Education (B.Ed.) cohorts in the junior primary phase have received in their fouryear training (Trudell et al., 2012). There appears to be several similarities between the BETD and B.Ed. modules related to understanding the concept of literacy/reading, applying different reading approaches and theories, using appropriate resources, and creating a literacy-friendly 
classroom. It seems that while both the BETD and B.Ed. modules for training reading instruction cover reading acquisition adequately, the $\mathrm{B}$.Ed. module is more current regarding the individual reader.

\section{Reading instruction}

Teaching methods used for reading acquisition should be considered a critical factor if there is to be a change (Moats, 1999). Thus, Bloch (1999) states that teachers need to acquire the necessary teaching skills that will bring about more literate learners. According to McGuinness (2004), the knowledge of how to teach children to read, write, and spell is highly developed; however, this highly developed knowledge has not been made available to educators, legislators, parents, and researchers. In fact, several teachers show a lack of knowledge of appropriate teaching methods (Moats \& Foorman, 2003). Thus, it seems this knowledge does not always filter down to teachers in the classroom who are teaching children how to read.

Moats (1999) and McGuinness (2004) contend that writing systems are inventions and not part of our biological inheritance like spoken language. As such, children need to be trained to read the writing system. Reading instruction should ensure that the nature and logic of the writing system are transparent to the learner. The authors also believe that a writing system was never based on whole words because languages have too many words for us to remember all of them. Thus, a reading method that is either totally or partially dependent on whole word memorization is bound to cause most children who use the system to fail. Incidental reading where children are compelled to recognize words instead of being able to decode them falls in this category. McGuinness (2005), Lyytinen, et al. (2009), Shanahan (2005) and others, including the United States National Reading Panel (National Reading Panel, 2000), maintain that teachers who teach the phonemic basis of the alphabet produce the most successful readers, especially in languages with transparent orthographies. This means that if teachers focus on teaching the phonemic basis of the alphabet, they can produce superior readers. In Namibia, the phonics-based approach to reading instruction is one of the teaching methods that is emphasized (Ministry of Education, 2005).

In their studies examining the methods that teachers in the Otjozondjupa and Kavango regions in Namibia use to teach reading, Mutenda (2008) and Kekhani-Mhoney (2015) found that most teachers did not use the methods that they were taught in their Basic Education Teachers Diploma (BETD) program in college. Rather, they used random methods, for example, drilling (making learners reread a text until they can do it well), that were unsubstantiated by the research literature. Furthermore, in Kekhani-Mhoney's (2015) study, 21 percent could not recall any of the teaching methods for reading instruction that they had been exposed to in college.

In conclusion, Ojanen et al. (2015) believe that studying the process of literacy in each language will assist in developing the most optimal method to teaching literacy in that particular language. It is this optimal instructional method that teachers need to know well in order to scaffold the reading acquisition process for learners.

\section{Teaching experience}

Many studies have shown that teacher quality affects how well learners perform. Teaching experience is regarded as an important factor which contributes to teacher quality (Rice, 2010; Rockoff, 2004). In an analysis of panel data from New Jersey school districts, Rockoff (2004) determined that teacher experience had statistically significant positive effects on reading test scores. Rice (2010) qualifies teaching experience by claiming that, in general, teachers who have more than 20 years of teaching experience perform better than teachers who have no experience, but that they are not necessarily better than teachers with at least five years of experience. She states that teachers show their greatest productivity advances during their first years of teaching and that it seems this burst of productivity levels off after this period. So, 
while it appears teaching experience is a strong teacher quality, increased years of teaching does not necessarily equate to increased gains for learners.

\section{Class size}

Scaffolding as an instructional tool is based on providing the optimal support to an individual learner. The more learners there are, the more difficult it is to provide individual scaffolding. Like most African countries, Namibian classes are larger than the average developed country. The countries belonging to the Organisation for Economic Co-operation and Development (OECD) had an average of 21.4 learners per classroom in primary school (Rampell, 2009), while of the countries that exceed 40:1, sub-Saharan Africa and Asia have the highest learner to teacher ratio (Benbow, Mizrachi, Oliver, \& Said-Moshiro, 2007). How does class size impact on learning and teaching? Benbow, et al. (2007) state that the research analysis has varying results. There is an argument for the positive impact that smaller classes have on learner achievement, while at the same time there is evidence where small classes have no significant impact. The research results from the cited studies above, however, agree that smaller classes benefit learners who are disadvantaged and younger learners. In fact, they claim that for younger learners the benefits gained from smaller classes extend into higher grades.

Mueller (2013) found that the more experienced teachers only outperformed the rest when the class size was small. According to Mueller, this effect was, however, more likely due to greater quality of teaching than due to fewer class disruptions. A study carried out by Harfitt (2012) examined teachers' perceptions and their teaching approaches on both large (39-41 learners) and small (21-25) classes. He found that teachers' lesson plans and teaching approaches were the same for both groups. The differences were in how teachers perceived the two class groups. They cited classroom management issues for large classes (noise, disruptions) and had a more positive outlook to learners in small classes. They admitted to knowing learners in small classes better in terms of the learners' learning strategies and their personalities. In terms of classroom discourse analysis, they addressed far more questions to individual learners in a smaller class and these questions tended to be more open-ended than for a large class. The teachers had more personalised interactions in smaller classes, as well as more group work.

In her study examining the reading methods used by Bachelor of Education Teachers Diploma (BETD) teachers in the Kavango region in Namibia, Kekhani-Mhoney (2015) found that the majority of teachers $(81 \%)$ in the study claimed that the success of reading lessons was dependent upon class size rather than the teaching methods used. They were of the opinion that the larger the class size the more difficult it is to teach reading in these classes. One of the teachers claimed that large classes made it difficult for her to support learners who were at-risk for reading difficulties. Kekhani-Mhoney echoes the findings of Harfitt (2012) that found that learners in large classes do not receive much individual attention from teachers. At the time of her study, there were classes in the Kavango region that had 65 learners. The class size of Grade 1 learners in Windhoek where the study took place had an average of 40 learners per class. Consequently, the question is how the class size impacts the support that teachers provide to the Grade 1 classes.

\section{Teachers' knowledge}

As a result of the findings from a survey carried out in the United Kingdom by the Office for Standards in Education, Children's Services and Skills, known as Ofsted, characteristics of the best newly qualified teachers were determined (Ofsted, 2012). These teachers have a very good understanding of language development in children and its link to reading acquisition. Because of their strong knowledge of language development and reading acquisition, these teachers can support learners across ability and age groups. They demonstrate good knowledge of phonics and how it supports reading and spelling. This level of knowledge is what is expected of all teachers who are guiding children through the process of reading acquisition. However, reality may not always reflect this scenario. 
Bos, Mather, Dickson, Podhajski, and Chard (2001) examined the perceptions and knowledge of both pre- and in-service teachers regarding early reading instruction. The findings reflect that teachers had limited knowledge of phonological awareness, phonics, and language structure. They also perceived themselves to be lacking in skills related to teaching reading. Moats and Foorman (2003) carried out a survey as part of a longitudinal study to determine the reading-related content knowledge (i.e., the sounds, words, sentences, and principles of instruction) of kindergarten to fourth-grade teachers in low-performing, high-poverty urban schools similar to the Windhoek schools that formed part of this study. Their findings showed that there is an overall modest predictive relationship between teachers' knowledge, classroom reading achievement levels, and teachers' observed teaching competence, and the associations between them increased significantly by the third and fourth grades.

In a study to determine the extent of early educators' knowledge of early literacy development in the United States, Crim, Hawkins, Thornton, Rosof, and Copley (2008) determined that these teachers had difficulty identifying specific print-to-speech concepts of the English language structure, meaning the basic skills related to beginning reading instruction. They listed these skills to include counting syllables in words and identifying the number of morphemes and phonemes in words. Regarding separating words into syllables, the success of teachers who formed part of the study ranged between $68 \%$ and $95 \%$. In perfect contrast, the teachers had an inaccuracy rate ranging between $68 \%$ and $95 \%$ in identifying the number of morphemes in a word. There was a wider range of inaccuracy $(40-85 \%)$ in identifying the number of phonemes in words. Crim et al. (2008) conclude that although most teachers could correctly separate words into syllables, some struggled to carry out the task. This implies that, as these teachers cannot correctly identify syllables, they will be unable to assist their learners in learning how to identify them correctly. The worst performance from teachers came from the area of morpheme identification, and if teachers do not understand the structure of words, they will be unable to create a solid foundation for learners in phonological awareness.

Due to the findings indicating that some early childhood educators do not make the link between phonological awareness (e.g., syllabification, morpheme identification, and phoneme identification) and early literacy acquisition, the researchers recommend that teacher training programs ensure early childhood educators have a strong basic knowledge of early literacy skills. Failure to train teacher educators in the important area of phonological awareness poses a risk to their learners' reading achievement.

All these studies recommend that pre-service teacher education should ensure that teachers have the core knowledge of language constructs that are required in teaching reading, especially in the early grades, irrespective of the transparency of the orthography of the classroom language used. Continuous professional development programs should address the misconceptions that teachers appear to have about their knowledge of language constructs and their actual lack of critical knowledge.

\section{Methods}

\section{Participants}

The participants in the study were Grade 1 teachers $(N=132)$ in Windhoek, the Namibian capital (Khomas Region), who completed a survey to determine their perceptions and knowledge of reading instruction. Of the government primary schools in the Khomas Region, 34 schools were surveyed (Ministry of Education: Directorate of Planning and Development, 2013).

\section{Measures and Procedures}

A questionnaire based on the research questions was developed for this study based, inter alia, on previous ideas from the OECD Teaching and Learning International Survey (TALIS) Teacher Questionnaire (International Project Consortium, 2008) and the Teacher Knowledge of Literacy Content: Evaluation of Delaware Reading First (Ackerman, Grusenmeyer, Nian, \& 
Qiao, 2008). The survey consisted of the details of the teacher characteristics (e.g., personal details, teacher training, and their classroom size and situation), their specific training in reading instruction, reading methods and materials they used, their beliefs about early reading and spelling instruction, and their knowledge of the structure of the Namibian languages offered at these schools, including English.

The survey questionnaire was developed into an electronic format using an application called SurveyGizmo and then downloaded onto ten tablets. After gaining permission from the Ministry of Education, snowball sampling was used to collect the data by going to a school and identifying the Grade 1 teachers. The mean number of Grade 1 classes per school was four, and those teachers were surveyed. After explaining the purpose of the research study to teachers and obtaining their permission to participate in the data collection, they were shown how to complete the electronic questionnaire. As this was the first opportunity they had had to complete a questionnaire in this manner, they found the experience 'enjoyable' and different from the usual paper and pen questionnaires. After data collection at a school was completed, the next school in the area was visited. This process of moving from school to school and area to area in the city of Windhoek lasted until the target of at least 100 completed questionnaires (for statistical and thus generalizability purposes) was accomplished (1 month).

\section{Data analysis}

The survey data ranged from nominal to ordinal scale, with several variables presented as ordinal data, which is typical when gathering views through surveys. Data analysis included mainly descriptive statistics consisting of frequencies and cross-tabulations.

\section{Results}

The results of this study describe the demographics of the Grade 1 teachers who formed part of the study, teachers' recognition of good reading instruction, teachers' reading instruction practices in classrooms, and teachers' knowledge of key reading components. The section concludes with a summary of the important results.

\section{Demographics}

Most of the Grade 1 teachers (84\%) were $30-60$ years of age, with the largest age group being $30-49(59 \%)$. The teachers' mean overall teaching experience was 15.8 years $(S E=.98, S D=$ $11.25, \min =0, \max =44$ ), while the mean teaching experience in Grade 1 was 9.5 years ( $S E$ $=.85, S D=9.69, \min =0, \max =44)$. The mean class size was 40.1 students $(S E=.35, S D$ $=3.56, \min =15, \max =46$ ). The smallest class was a special education class (i.e. a separate class at selected Namibian schools for learners who had learning difficulties; sometimes it was a multi-grade class). $3.9 \%$ of the teachers had more than 44 learners in their class and they claim to have small groups for reading. Conversely, $14.4 \%$ of teachers claim large classes as the reason for not having small groups as part of their reading instruction methods. Most of the teachers (91\%) had at least a teaching diploma which is the current acceptable standard in Namibia; alarmingly, almost a third of the teachers (32\%) claim they did not have training in reading instruction. Most teachers (82\%) rated the quality of training in reading instruction as average, above average, or excellent, while $5.9 \%$ rated it as extremely poor or below average.

\section{Teachers' recognition of good reading instruction}

Teachers' beliefs regarding early reading and spelling instruction were measured via statements using a 5-point Likert scale. The results show that most $(97 \%)$ of the teachers agree with these statements about good reading and language instruction. In fact, the biggest response was from those that strongly agree $(66 \%)$.

Teachers' reading instruction practices in classrooms

To gauge their use of reading practices, teachers were asked about the number of teaching methods they use, the specific instruction content they use, how they create a literate 
classroom, how they encourage and support poor readers, and whether and how reading instruction in small groups occurs. Their responses are presented below.

(1) Number of teaching methods used. Teachers reported that they mostly use a range of methods when teaching reading (83\%), while $15 \%$ report using only one method. Regarding how teachers develop their learners' understanding of 'phonological units', most teachers $(82 \%)$ tend to do so from smaller units of speech (i.e. phonemes, morphemes) to larger units of speech (i.e. syllables, words) rather than the opposite approach (9\%). In both these survey questions, $6 \%$ reported that they do not understand these concepts.

(2) Specific instruction content regarding language and reading skills. Figure 2 describes the specific instruction content concerning language and reading skills that teachers use in their classrooms. Teachers could select one or more from a list of seven. The figure shows each of the specific instruction content either selected or not totaling the 132 teachers in the survey, for example phonological awareness was selected by 119 teachers and not selected 13 teachers, while word features was selected by 44 teachers and not selected by 88 teachers.

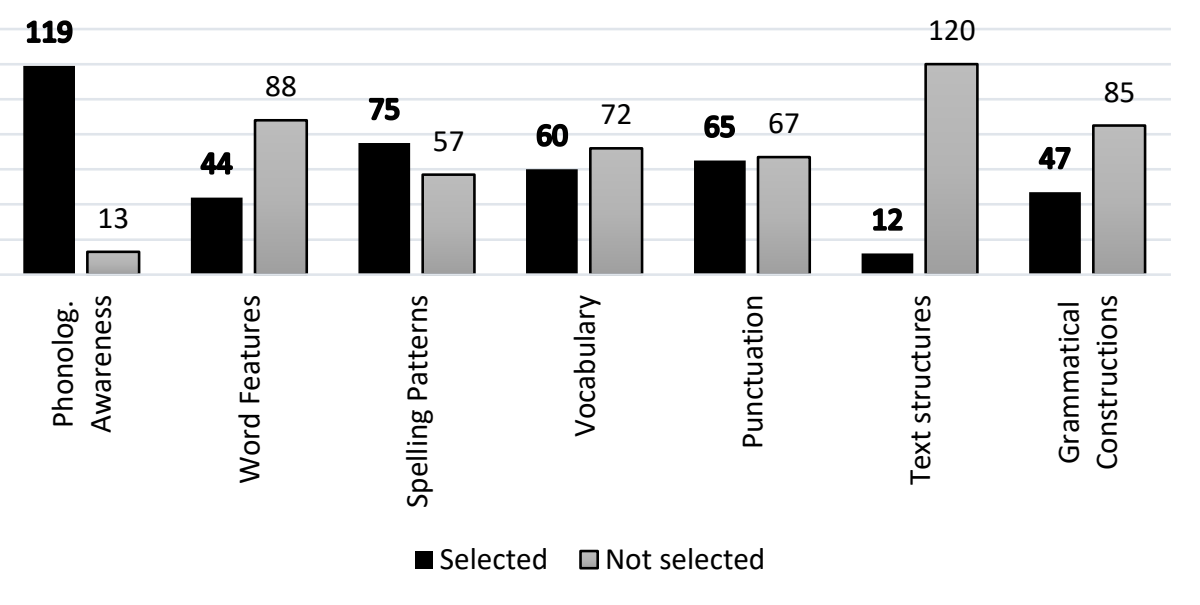

Note: Teachers could select more than one alternative.

Figure 2. Specific instruction content concerning language and reading skills

As Figure 2 demonstrates that most teachers, for instatnce 119 of the 132 teachers $(90 \%)$, included phonological awareness as part of their reading instruction content, more so than the other reading and language skills. After aggregating their selections, 42 combinations emerged. Two aggregated combinations noticeably had the most responses. Phonological awareness as a response on its own was selected by 30 teachers. A combination of six language and reading skills including phonological awareness, word features and their structures, spelling patterns, vocabulary and word study, grammatical constructions, and punctuation was selected by 11 teachers. The other 40 combinations were selected by a range of 1 to 6 teachers. One teacher used none of these practices, while one teacher claimed not to understand these concepts.

(3) Creating a literate classroom. Teachers were asked about the practices they use to create a literate classroom environment. They could select a combination of the following practices: encouraging children to write for a range of audiences, incorporating literacy materials in dramatic play areas, and using labels and notices. The use of labels and notices to draw children's attention to literacy was the practice that most teachers selected ( $80 \%)$, as well as in combination with other practices. The teachers who indicated that they use other practices mentioned, inter alia, that they collect story books with pictures that attract learners' attention, use word strips to build sentences, and use posters, rhymes, pictures, stories, songs and games. 
(4) Encouraging poor readers. To encourage struggling readers to read, teachers indicated they use the following strategies reported in Figure 3 in their selection of texts for poor readers, either on their own or in combination.

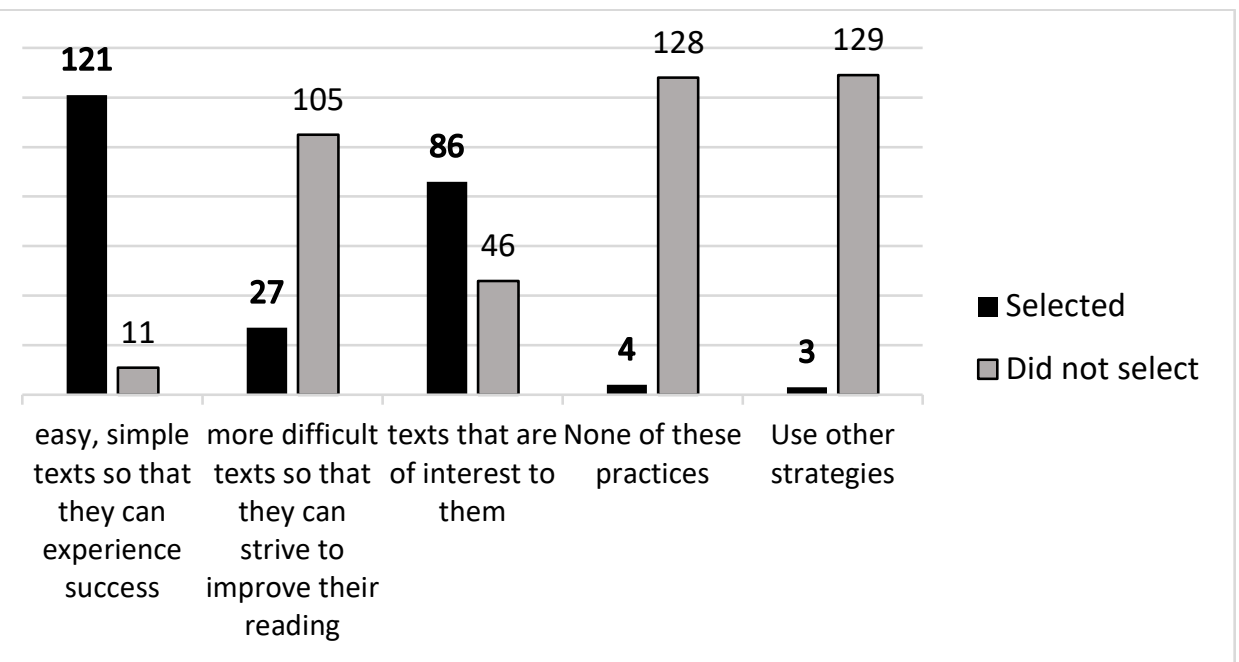

Note: Teachers could select more than one alternative.

Figure 3. Encouraging poor readers to read

Using simple, easy texts so that poor readers can experience success was the strategy most teachers selected either on its own or in combination with other strategies used to encourage poor readers to read (92\%). Other strategies that teachers mentioned using include providing learners with theme-related texts or reading material, using pictures for them to make up their own stories, including more reading activities that the parents help them with when at home, and having a reading corner where students select a story of interest and read independently.

(5) Reading instruction in small groups. Teachers responded to the different strategies and practices they used to facilitate small-group instruction as described in Figure 4.

\section{Reading instruction in small groups}

divide the class into small groups with similar reading abilities

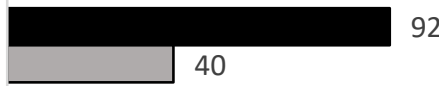

texts and instruction are matched to the small group

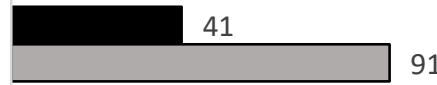

- Selected $\square$ Did not select

evaluate learners regularly and regroup as needed

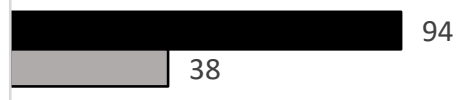

plan tasks for rest of class while busy with a small group

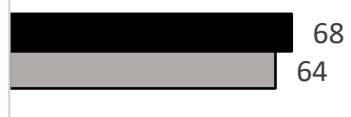

large class size prevent small group instruction

Note: Teachers could select more than one alternative.

Figure 4. Reading instruction in small groups 
Most teachers indicated that they used a combination of these strategies. Of the 19 teachers who responded that their large classes prevented them from having small group instruction, $37 \%$ indicated that they also evaluate learners regularly and regroup learners as their progress changes.

\section{Teachers' knowledge of key reading components}

This section describes teachers' knowledge regarding certain language and reading components and examines the possible connection between the training that teachers state they received in reading instruction and their knowledge of phonics as a reading instruction method.

(1) Teachers' knowledge of language and reading components. Figure 5 displays the knowledge that the teachers possess related to language and reading components. The black bars indicate the number of teachers that answered correctly, while the grey bars indicate the number of teachers who had incorrect answers (totaling the 132 Grade 1 teachers for each knowledge statement in Figure 5). The bottom group of black and grey bars show the overall percentage for correct and incorrect answers, respectively. The results revealed that teachers lacked knowledge about some language and aspects of reading with an inaccuracy rate between $50 \%$ and $97 \%$. The results demonstrate that the knowledge question asking teachers to identify the word that has incorrect syllable division is the only question that most teachers $(69 \%)$ answered correctly. Most teachers answered the other questions incorrectly, ranging from $51 \%$ to $98 \%$ incorrect (Figure 5).

Reading method:speech sounds to letters-Phonics

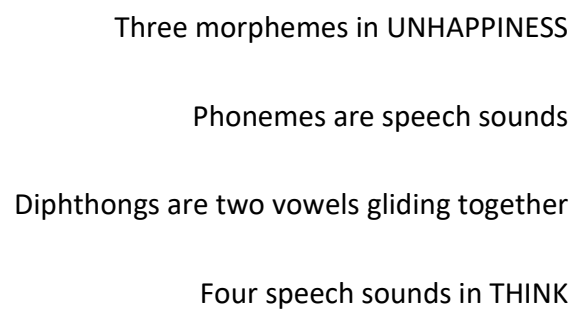

Incorrect syllable division - UN-I-FORM

Average knowledge \%

- Correct Answer

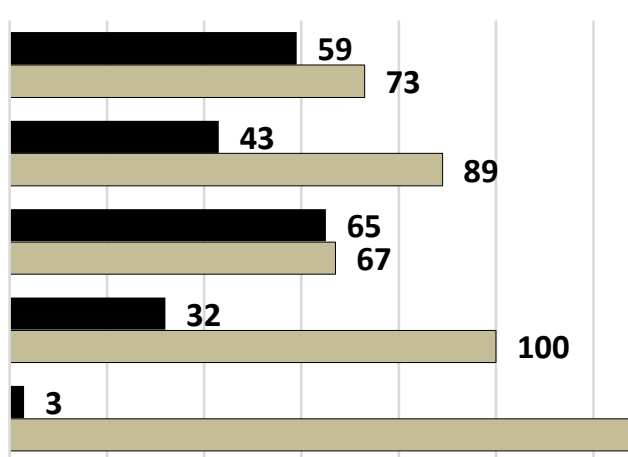

129

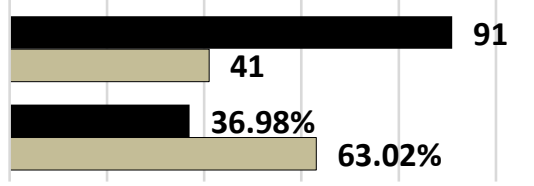

$\square$ Incorrect Answer

Figure 5. Knowledge about key aspects of reading

(2) The connection between training received in reading instruction and teachers' knowledge of phonics as a reading method. According to the Namibian curriculum for the junior primary phase, phonics is a preferred method of teaching reading in Namibia, as most of the local languages have transparent or regular orthographies. More than half of the teachers (55\%) were unable to correctly identify that phonics is a reading method. Of these, the majority (almost 60\%) claimed to have received training in reading instruction.

\section{Summary of the results}

While most teachers $(81 \%)$ claim that they have received average to excellent training in teaching reading and demonstrate that they overwhelmingly agree $(99 \%)$ with good reading 
practices and beliefs, the results reveal that their actual knowledge of various aspects of reading does not relate to their stated teacher training and reading beliefs. To gauge their use of reading practices, teachers were asked about the number of teaching methods they use, the specific instruction content they use, how they create a literate classroom, how they encourage and support poor readers, and whether and how reading instruction in small groups occurs. Teachers reported that they mostly use a range of methods when teaching reading $(83 \%)$, while (15\%) report using only one method. Of all the reading and language skills that teachers had to select from, $90 \%$ included phonological awareness as part of their reading instruction content, more so than the other reading and language skills. Among different strategies used to create a literate environment in the classroom, the majority (82\%) use labels and notices to draw children's attention to literacy. To encourage struggling readers to read, teachers indicated they mainly use simple, easy texts so that poor readers can experience success. It appears that the overall average for the knowledge section showed that less than $37 \%$ of teachers had detailed knowledge of specific aspects of reading such as being able to identify syllables, morphemes, and speech sounds in words as well as demonstrating knowledge of phonics, phonemes, and diphthongs.

\section{Discussion}

In terms of teaching experience, the teachers in the study had a mean overall teaching experience of 15.8 years, while the mean teaching experience in Grade 1 was 9.5 years. According to Rice (2010), this quantity of teaching experience is good as it is at least five years of experience. Furthermore, Mackenzie, Hemmings, and Kay (2011) found that teachers who had more experience in teaching learners in early grades, as compared to general teaching, tended strongly towards a Vygotskian approach to the teaching and learning of literacy, where instructional scaffolding is key to successful learning. This should bode well for Namibian teachers in the study in terms of their potential to scaffold learning opportunities in reading instruction to suit the needs of the learner.

The mean class size for the study was 40.1 and while a small percentage of teachers (3.9\%) with more than more than 44 learners in their class claim to have small groups for reading, more than $10 \%$ of teachers claim large classes as the reason for not having small groups as part of their reading instruction methods. Research has shown that, in general, smaller classes have a positive impact on learner achievement, especially for learners who have learning difficulties and younger learners (Benbow et al., 2007; Mueller, 2013; Kekhani-Mhoney, 2015). This was partly due to the positive perception that teachers had towards smaller classes (Harfitt, 2012). This outlook manifested itself in scaffolding activities such as addressing far more questions to individual learners as part of classroom discourse and these questions tended to be more open-ended than for a large class. The teachers had more personalized interactions in smaller classes, as well as more group work, which resulted in knowing learners better in terms of their learning strategies and their personalities.

Although most Namibian teachers in the study have adequate teacher training as required by the Namibian Ministry of Education, almost a third (32\%) claim that they did not receive training in reading instruction. This is a worrisome finding, as the importance of having teachers trained in reading instruction is emphasized by experts in the field of reading acquisition. These experts claim that reading acquisition, unlike language acquisition, is not a biological process (McGuinness, 2005) but a human invention (McGuinness, 2004) that is very complicated, and as such, teachers need to understand this process and implement their teaching practices accordingly (Lee, Gable, \& Klassen, 2012). That is why training in reading instruction is so important. This knowledge, that teachers should have, is especially important in understanding how reading is acquired in different languages, whether their orthographies are transparent or opaque (Furnes \& Samuelsson, 2011; Katzir et al., 2012; Lyytinen et al., 2009; Ojanen, 2007; Ojanen et al., 2015). 
An overwhelming majority of Grade 1 teachers (97\%) state that they can recognize good reading practices related to early reading and spelling instruction. Experts such as Ofsted (2012) claim that teachers' knowledge and recognition of good reading practices are key to their learners' successful reading acquisition. Most Grade 1 teachers also use multiple methods to successfully teach aspects of reading. Teachers also indicated that they use different practices to create a literate environment. These practices include, as the most widely used, the use of labels and notices to draw children's attention to the use of literacy. To encourage poor readers to read, teachers indicated they use a variety of practices, the most widely used being selecting simple, easy texts so poor readers can experience success. These practices resonate with what experts and researchers have shown as examples of scaffolding. Van de Pol, Volman, and Beishuizen (2010) characterize this stage of scaffolding, where teachers support their learners based on their level of need, as contingency. The other two characteristics that they discuss, namely, fading and transfer of responsibility whereby teachers withdraw their support gradually are not evidenced in the study. This is because the study did not directly elicit responses to these characteristics.

With an inaccuracy rate between $50 \%$ and $97 \%$, the results revealed that teachers lacked knowledge about some language aspects of reading instruction. These findings mirror those of Crim et al. (2008), whose teachers performed poorly in identifying the number of morphemes and phonemes in a word (i.e. an inaccuracy rate between $40 \%$ and $95 \%$ ), while in contrast, they had accuracy rates ranging between $68 \%$ and $95 \%$ in the ability to separate words into syllables. The study carried out by Bos, Mather, Dickson, Podhajski, and Chard (2001) also showed that both pre- and in-service teachers showed limited knowledge in phonological awareness, phonics, and language structure. How does this limited knowledge impact teachers' ability to teach reading? Previous studies have shown a predictive relationship between teachers' knowledge of language development and their classroom practices, especially in the very early grades (Aro \& Björn, 2015; Moats \& Foorman, 2003). According to various studies (Alatalo, 2015; Aro \& Björn, 2015; Bos et al., 2001; Crim et al., 2008; Moats \& Foorman, 2003; Stark et al., 2016), there appears to be a tendency with regard to the limited knowledge of phonological awareness, phonics, and language structure that many teachers appear to have. It also appears that this limited knowledge on in-depth language structures may not have such adverse effects on the teachers' ability to teach reading effectively.

However, while Finnish teachers have a Masters' degree, Namibian Grade 1 teachers only need a basic teacher's diploma, for example. This is not only a difference of five years of teachers' training versus three years but also speaks to a higher level of training, specifically, a master's degree rather than a diploma. Therefore, even if some Finnish teachers may lack some knowledge of exact language structures (Aro \& Björn, 2015), their higher level of teacher training compensates in the successful methods they use to teach reading.

In addition to adequate teacher training, there are several other aspects that affect the teaching of reading in Namibia. Chief among them is the multilingual situation in Namibia, where learners are not necessarily taught to read in their mother tongue. Instead of being taught in the mother tongue with largely transparent orthographies, many learners are taught to read in English, which has an opaque orthography as well as not being the mother tongue of most of the teachers and students. Teacher training should ensure that teachers are trained adequately in how to teach reading in languages with both transparent and opaque orthographies since both are taught to learners during the junior primary phase.

\section{Conclusion}

As the above discussion indicates, successfully resolving several crucial issues could lead to improvements in how children learn to read in Namibia. These include mother-tongue instruction, higher teacher qualifications for junior primary teachers, better training in reading 
instruction, and of course, better reading resourced classrooms, among others. Many of these issues mentioned can only be addressed via long-term strategies. A number of them are currently being addressed, for example higher teacher qualifications for junior primary teachers at the University of Namibia. The introduction of the Bachelor of Education in Preand Lower Primary Education in 2011 will go a long way in raising the level of Grade 1 teachers' knowledge and professionalism. The Ministries of Education, both Higher and Basic Education, and teachers in general are encouraged to improve the teaching qualifications of both unqualified and underqualified teachers, as well as those with three-year teaching diplomas. Other issues may have short to mid-term solutions. One of these is to support teachers and more directly learners in addressing initial literacy acquisition, which is a step towards improving the critical reading situation in the country. According to Stanovich's (1986) Matthew effects in reading, the more a child reads (and loves to read), the better that child's reading becomes. Thus, ensuring that each Namibian classroom has a literate environment, where the love of books and reading is nurtured, should be a must for every classroom; more so in Grade 1 where initial reading is formally taught. Innovative strategies such as a digital reading tool as an intervention tool for teachers to use when assisting struggling readers who can get lost in large classroom situations could mitigate the crisis that leads to "the persistent poor results in English" described by the Deputy Minister of Education, Arts and Culture with regards to the Grade 12 examination in 2019.

\section{References}

Ackerman, C. M., Grusenmeyer, L. H., Nian, Q., \& Qiao, X. (2008). Teacher knowledge of literacy content: Evaluation of Delaware reading first. Retrieved from http://udspace.udel.edu/bitstream/handle/19716/3181/Teacher Knowledge DERF 4 2008 final.pdf; sequence $=1$

Alatalo, T. (2015). Professional content knowledge of grades one-three teachers in Sweden for reading and writing instruction: language structures, code concepts, and spelling rules. Scandinavian Journal of Educational Research, (April 2015), 1-23. Retrieved from https://doi.org/10.1080/00313831.2015.1024734

Aro, M., \& Björn, P. M. (2015). Preservice and inservice teachers' knowledge of language constructs in Finland. Annals of Dyslexia. Retrieved from https://doi.org/10.1007/s11881-015-0118-7

Benbow, J., Mizrachi, A., Oliver, D., \& Said-Moshiro, L. (2007). Large Class Sizes in the Developing World: What Do We Know and What Can We Do? (No. Cooperative Agreement No. GDG-A_00-03-00006-00). Retrieved from http://pdf.usaid.gov/pdf_docs/PNADK328.pdf

Bloch, C. (1999). Literacy in the Early Years: Teaching and learning in multilingual early childhood classrooms. International Journal of Early Years Education, 7, 39-59.

Bos, C., Mather, N., Dickson, S., Podhajski, B., \& Chard, D. (2001). Perceptions and knowledge of preservice and inservice educators about early reading instruction. Annals of Dyslexia, 51(1), 97-120.

Crim, C., Hawkins, J., Thornton, J., Rosof, H. B., \& Copley, J. (2008). Early childhood educators' knowledge of early literacy development. Issues in Teacher Education, 17(1), 17-30. Retrieved from http://eric.ed.gov/?id=ED507867

Furnes, B., \& Samuelsson, S. (2011). Phonological awareness and rapid automatized naming predicting early development in reading and spelling: Results from a crosslinguistic longitudinal study. Learning and Individual Differences, 21(1), 85-95. Retrieved from https://doi.org/10.1016/j.lindif.2010.10.005

Harfitt, G. J. (2012). An examination of teachers' perceptions and practice when teaching large and reduced-size classes: Do teachers really teach them in the same way? Teaching and Teacher Education, 28(1), 132-140. Retrieved from https://doi.org/10.1016/j.tate.2011.09.001

likela, S., \& Oliviera, Y. (2020, January 10). Govt ponders English indaba. The Namibian, p. 1.

International Project Consortium. (2008). OECD teaching and learning international survey 
(TALIS): Teacher questionnaire (pp. 1-23). Retrieved from http://www.oecd.org/education/school/43081350.pdf

Katzir, T., Schiff, R., \& Kim, Y.-S. (2012). The effects of orthographic consistency on reading development: A within and between cross-linguistic study of fluency and accuracy among fourth grade English- and Hebrew-speaking children. Learning and Individual Differences, 22(6), 673-679. Retrieved from https://doi.org/10.1016/j.lindif.2012.07.002

Kekhani-Mhoney, M. J. (2015). An Investigation of reading methods used by basic education teaching diploma (BETD) primary school teachers in the Kavango education region of Namibia (University of Namibia). Retrieved from http://hdl.handle.net/11070/1601

Lee, G.-L., Gable, R., \& Klassen, V. K. (2012). Effective reading remediation instructional strategies for struggling early readers. Procedia - Social and Behavioral Sciences, 46, 822-827. Retrieved from https://doi.org/10.1016/j.sbspro.2012.05.206

Lyytinen, H., Erskine, J., Kujala, J., Ojanen, E., \& Richardson, U. (2009). In search of a science-based application: A learning tool for reading acquisition. Scandinavian Journal of Psychology, 50(6), 668-675. Retrieved from https://doi.org/10.1111/j.1467-9450.2009.00791.x

Mackenzie, N. M., Hemmings, B., \& Kay, R. (2011). How does teaching experience affect attitudes towards literacy learning in the early years? Issues in Educational Research, 21(3), 281-294.

McGuinness, D. (2004). Early reading instruction: What science really tells us about how to teach reading. Massachusetts: MIT Press.

McGuinness, D. (2005). Language development and learning to read: the scientific study of how language development affects reading skill. Massachusetts: MIT Press.

Ministry of Education: Directorate of Planning and Development. (2013). Education Management Information System (EMIS): Education Statistics, 2012. Retrieved from https://doi.org/ISSN 2026-7533

Ministry of Education. (2005). Curriculum for the lower primary phase: English version. Okahandja, Republic of Namibia.

Moats, L. C., \& Foorman, B. R. (2003). Measuring teachers' content knowledge of language and reading. Annals of Dyslexia, 53(1), 23-45. Retrieved from https://doi.org/10.1007/s11881-003-0003-7

Moats, L. C. (1999). Teaching reading is rocket science: What expert teachers of reading should know and be able to do. Washington, DC.

Mueller, S. (2013). Teacher experience and the class size effect-Experimental evidence. Journal of Public Economics, 98, 44-52. Retrieved from https://doi.org/10.10.1016/j.pubeco.2012.12.001

Mutenda, J. (2008). Teaching reading in grade 4 Namibian classrooms: A case study. Rhodes University, Grahamstown.

National Reading Panel. (2000). Teaching children to read: An evidence-based assessment of the scientific research literature on reading and its implications for reading instruction. In NIH Publication No. 00-4769 (Vol. 7). Retrieved from https://doi.org/10.1002/ppul.1950070418

Office for Standards in Education Children's Services and Skills. (Ofsted) (2012). From training to teaching early language and literacy: The effectiveness of training to teach language and literacy in primary schools. Retrieved from http://www.ofsted.gov.uk/sites/default/files/documents/surveys-and-goodpractice/f/From training to teaching early language and literacy.pdf

Ojanen, E., Ronimus, M., Ahonen, T., Chansa-Kabali, T., February, P., Jere-Folotiya, J., ... Lyytinen, H. (2015). GraphoGame-A catalyst for multi-level promotion of literacy in diverse contexts. Frontiers in Psychology, 6(May). Retrieved from https://doi.org/10.3389/fpsyg.2015.00671

Ojanen, E. (2007). Sewero La-ma-u: A phonetic approach to literacy teaching in Zambia. Ojanen, E., Ronimus, M., Ahonen, T., Chansa-Kabali, T., February, P., Jere-Folotiya, J., ... Lyytinen, H. (2015). GraphoGame: A catalyst for multi-level promotion of literacy in diverse contexts. Frontiers in Psychology, 6(June), 1-13. Retrieved from 
https://doi.org/10.3389/fpsyg.2015.00671

Rampell, C. (2009). Class Size Around the World. Retrieved from https://economix.blogs.nytimes.com/2009/09/11/class-size-around-the-world/

Rice, J. K. (2010). The impact of teacher experience: Examining the evidence and policy implications. Retrieved from http://www.urban.org/uploadedpdf/1001455-impactteacher-experience.pdf

Rockoff, J. E. (2004). The impact of individual teachers on student achievement: Evidence from panel data. The American Economic Review, 94(2), 247-252. Retrieved from http://www.jstor.org/stable/3592891

Saine, N. L., Lerkkanen, M. K., Ahonen, T., Tolvanen, A., \& Lyytinen, H. (2010). Predicting word-level reading fluency outcomes in three contrastive groups: Remedial and computer-assisted remedial reading intervention, and mainstream instruction. Learning and Individual Differences, 20(5), 402-414. Retrieved from https://doi.org/10.1016/j.lindif.2010.06.004

Shanahan, T. (2005). The national reading panel report: Practical advice for teachers. Learning Point Associates/North Central Regional ..., 1, 41-47. Retrieved from http://eric.ed.gov/ERICWebPortal/recordDetail?accno=ED489535

Stanovich, K. E. (1986). Matthew effects in reading: Some consequences of individual differences in the acquisition of literacy. Reading Research Quarterly, 21(4), 360-407. Retrieved from https://www.researchgate.net/publication/230853161_Matthew_Effects_in_Reading_So me_Consequences_of_Individual_Differences_in_the_Acquisition_of_Literacy

Stark, H. L., Snow, P. C., Eadie, P. A., \& Goldfeld, S. R. (2016). Language and reading instruction in early years' classrooms: the knowledge and self-rated ability of Australian teachers. Annals of Dyslexia, 66(1), 28-54. Retrieved from https://doi.org/10.1007/s11881-015-0112-0

Trudell, B., Dowd, A. J., Piper, B., \& Bloch, C. (2012). Early grade literacy in African classrooms: Lessons learned and future directions. Tunisia.

UNESCO. (2013). Assessment of teacher training and development needs to ensure Education For All (EFA): Needs Assessment Report. Paris.

van de Pol, J., Volman, M., \& Beishuizen, J. (2010). Scaffolding in teacher-student interaction: A decade of research. Educational Psychology Review, 22(3), 271-296. https://doi.org/10.1007/s10648-010-9127-6 